\title{
Methodology and characterization of an in vitro perfusion model for the mouse ovary
}

\author{
M. Brännström ${ }^{1}$ and S. Flaherty ${ }^{2}$ \\ ${ }^{1}$ Department of Obstetrics and Gynaecology, University of Göteborg, Sahlgrenska Hospital, \\ S-41345 Göteborg, Sweden; and ${ }^{2}$ Department of Obstetrics and Gynaecology. The University of Adelaide, \\ The Queen Elizabeth Hospital, Woodville, South Australia 5011. Australia
}

\begin{abstract}
Perfusion of intact ovaries in vitro has proved to be a suitable model for the study of ovarian events, such as ovulation and corpus luteum function, with advantages over cell culture systems of preserved three-dimensional structure with intact intercellular communication. This methodology has been described for several larger experimental animals. Development of genetically manipulated mouse strains and the larger availability of recombinant proteins and monoclonal antibodies in this species prompted the development of a mouse ovary perfusion system. In the present study, we describe the methodology for perfusion of mouse ovaries in vitro and characterize the model with respect to steroidogenesis, ovulatory efficiency and morphology. Swiss mice ( $30-45 \mathrm{~g})$ were synchronized with a single injection of a GnRH agonist and laparotomy was peformed on the morning of pro-oestrus. The right ovary and its vasculature, after cannulation on the arterial side, were surgically isolated and transferred to a recirculating perfusion system, and were perfused for $20 \mathrm{~h}$. The ultrastructure of the ovaries after $20 \mathrm{~h}$ of perfusion was examined by transmission electron microscopy, which showed well-preserved cellular organelles and nuclei and distinct tight junctions between endothelial cells. Unstimulated ovaries did not ovulate and secreted small quantities of progesterone. After addition of hCG $(50 \mathrm{iu})$ or ovine $\mathrm{LH}\left(0.1 \mu \mathrm{g} \mathrm{ml}^{-1}\right)$, ovulations were observed in all perfused ovaries $(2.6 \pm 0.5$ and $2.0 \pm 0.3$ ovulations per treated ovary, respectively). There was a distinct rise in progesterone output after hormone addition. When a phosphodiesterase inhibitor, isobutylmethylxanthine $\left(0.2 \mu \mathrm{mol} 1^{-1}\right)$, was added in combination with $\mathrm{LH}$, the ovulation rate $(7.4 \pm 1.2)$ was similar to that in vivo and progesterone secretion was further increased compared with other treatments. Since the mouse has become a very important experimental animal in medical research and we have the ability to genetically manipulate this species, this methodology for perfusing mouse ovaries in vitro may be a useful tool in future studies of ovarian physiology.
\end{abstract}

\section{Introduction}

Perfusion of mammalian organs in vitro has been extensively used for studies of whole organ functions. A short-term in vitro perfusion methodology to study steroidogenesis in human ovaries was reported more than 30 years ago (Romanoff and Pincus, 1962). This technique was later adopted for longer term (>10 h) in vitro perfusions of human (Stähler et al., 1974), rabbit (Janson et al., 1982) and rat (Brännström et al., 1987) ovaries to study physiological processes, such as ovulation (Brännström and Janson, 1991) and the regulation of corpus luteum function (Sogn et al., 1984). This method has also proved to be the only consistent method for inducing ovulation in vitro (Brännström and Janson, 1991). Furthermore, oocytes ovulated during in vitro perfusion of rabbit ovaries successfully underwent fertilization and normal pregnancies were established (Kobayashi et al., 1983).

Received 24 April 1995.
Growth factors and cytokines are known to play important roles in ovarian physiology (Adashi et al., 1985; Brännström and Norman, 1993). With the development of recombinant proteins, monoclonal antibodies with neutralizing capacity and genetically manipulated animals, it has become increasingly possible to study the action of growth factors and cytokines. These experimental tools are commonly available for the mouse, whereas they are less readily available for rats and rabbits. Moreover, the availability of inbred mouse strains with special characteristics and the present knowledge of mouse genetics are much greater than those of any other animal (Paigen, 1995).

Possibly owing to the small size of the mouse and the extensive surgery involved in preparation of the isolated ovary, there are no published reports on perfusion of the mouse ovary to study metabolic and functional events. In this study we report, for the first time, the methodology involved in the successful in vitro perfusion of the mouse ovary with induction of ovulation in vitro. 


\section{Materials and Methods}

\section{Hormones and chemicals}

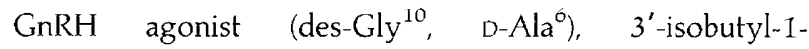
methylxanthine (IBMX), and gentamycin sulfate were purchased from Sigma (St Louis, MO). Ovine luteinizing hormone (NIH-LH-o25) was provided by NIDDK (Bethesda, MD) and the National Hormone and Pituitary Program (University of Maryland School of Medicine, Baltimore, MD). Bovine serum albumin (fraction $\mathrm{V}$ ) was from Boehringer (Mannheim), heparin sulfate from Fisons (Thornleigh, NSW), insulin from NOVO (Copenhagen) and hCG from Organon (Oss, The Netherlands).

\section{Animals}

Female, unmated Swiss mice (University of Adelaide Central Animal Facility) of 4-6 months age (weighing 30-45 g) were kept under controlled conditions ( $14 \mathrm{~h}$ light:10 $\mathrm{h}$ dark) and fed water and pellets ad libitum. During the study, it became obvious that the leaner animals $(<35 \mathrm{~g})$ were most suitable for surgery, owing to less intra-abdominal and retroperitoneal adipose tissue. The oestrous cycles of animals were synchronized using a modification of a procedure described by Vickery and McRae (1980); $20 \mu \mathrm{g}$ of a GnRH agonist was injected i.p. at $12: 00 \mathrm{~h}$ and mice were checked for pro-oestrus vaginal smears 3 days later. At this time, $80 \%$ of the animals exhibited pro-oestrus vaginal smears and this cycle was further confirmed by the presence of uterine fluid accumulation (Armstrong, 1968). Six animals were set aside and allowed to ovulate spontaneously in vivo. They were killed at oestrus and the number of oocytes in the ampullary region of the oviduct was counted under a microscope. The ovulation rate per ovary in these animals was $7.8 \pm 2.3$.

\section{Surgical technique}

The surgical procedure used was a modification of the preparation of the rat ovary as described by Brännström et al. (1987) but with major differences due to the different vascular anatomy (Fig. 1) and the smaller size of the mouse.

On the morning of induced pro-oestrus, the mice were anaesthetized with an i.p. injection of ketamine:xylazine (60:10 $\mathrm{mg}^{-1}$ body mass) followed by an i.p. injection of heparin (100 iu per animal). The right ovary with its vasculature was then isolated surgically. As the ovarian arteries of the mouse are too small to cannulate easily, the aorta was cannulated, with appropriate ligatures to direct the perfusion medium to the ovary. Only the right ovary from each mouse could be used, owing to the branching of the ovarian artery directly from the aorta on this side, as opposed to from the renal vessels on the left side (Fig. 1). The space in between the branching of the ovarian vessels and the kidney on the left side is too small to allow ligation without compromising ovarian flow.

The abdomen of the mouse was opened by a midline incision from the xiphoid process to the symphysis pubis. At this stage, the uterine horns were inspected for accumulation of fluid within the lumen of the uterus to ensure a pro-oestrous

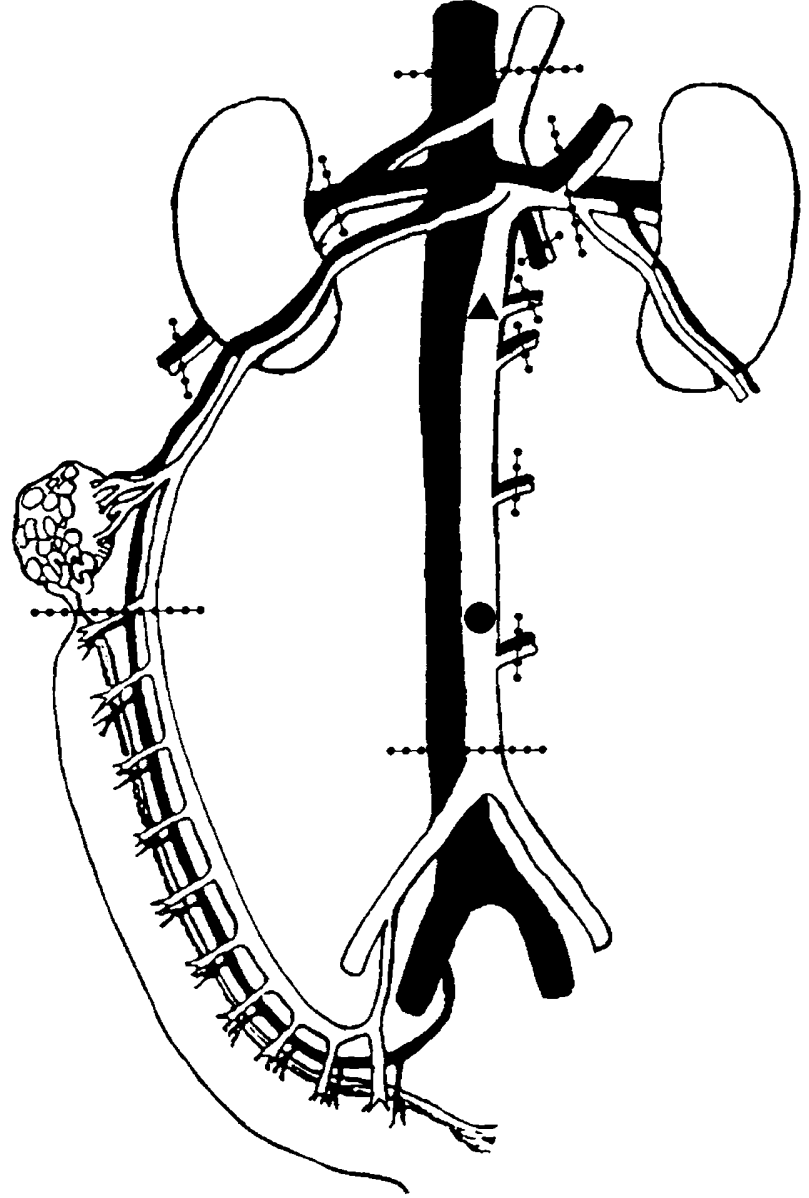

Fig. 1. Illustration of the vascular anatomy of the mouse with ligatures indicated by dotted lines. $\boldsymbol{0}$, point of cannulation; $\boldsymbol{\Delta}$ position of catheter tip.

stage (Armstrong, 1968). The distal mesenteric artery was clamped and then cut between the clamp and the colon. The distal part of the colon was double ligated and resected in between ligatures followed by separation of the intestines from the retro-abdominal wall through dissection through the dorsal mesenterium. Ligation of the left renal and suprarenal vessels was then performed, followed by excision of the left kidney. The left iliolumbar artery and vein were dorsal to the renal vessels and were subsequently double ligated and severed. The renal capsule on the right side was slit open by gentle pulling with forceps, followed by ligation of the vessels and excision of the kidney.

The right uterine branch of the ovarian artery and the uterine horn were ligated at the utero-tubal junction. By gentle dissection on the left side of the aorta and vena cava, three or four unpaired dorsal lumbar arteries were identified and then ligated. The accessible parts of these vessels were short and did not allow double ligation. Severance of the vessels was performed distal to the single ligatures at a later stage, towards the end of the operation. The vena cava and aorta were ligated just cranial to the iliac bifurcation, and cranial to this, a second suture was placed under the vena cava. The aorta was then tensioned by pulling the suture at the bifurcation and the aorta was cannulated in a retrograde direction with a $20 \mathrm{G}$ Teflon 
catheter; the tip of the catheter was advanced to a position $2 \mathrm{~mm}$ from the branching of the right ovarian artery (Fig. 1). The aortic catheter was tied in place with the suture previously under the vena cava, which now included the vena cava, the aorta and the inserted catheter.

The right ovary was then freed from adherent tissue and the suspensory ligament was cut. The ovarian bursa was slit open and carefully peeled back. The ovary was gently lifted up and moved towards the centre to expose the left iliolumbar artery and vein, which were double ligated and severed. The lumbar dorsal arteries were then cut distal to the sutures which previously had been ligated. The aortic catheter was opened for a short time to allow flushing of the catheter. The aorta and vena cava were then ligated together cranial to the branching of the renal vessels, followed by severance of the vessels cranial to this ligature and caudal to the insertion sites of the cannulae. The vena cava was cut open to enable perfusate to escape after it had been through the ovary. The surgical procedure took approximately $30 \mathrm{~min}$. The preparation was removed and placed in a small beaker with warm $\left(37^{\circ} \mathrm{C}\right) 0.9 \%$ $w / \mathrm{v} \mathrm{NaCl}$.

To remove all blood from the preparation and to ensure a functional specimen, the preparation was perfused at this stage with $0.9 \% \mathrm{w} / \mathrm{v} \mathrm{NaCl}$ administered by gentle use of a fine syringe or with an i.v. infusion container. During this procedure, the ovary became progressively paler in colour, as the blood was displaced from the specimen. The preparation was considered acceptable for perfusion if there was no visible arterial leakage, the blood flowed from the vena cava opening, and the ovary blanched after perfusion with saline.

\section{Perfusion apparatus and procedures}

The perfusion apparatus (Fig. 2) was a further development of the apparatus previously used for the rabbit and rat ovary (Janson et al., 1982; Brännström et al., 1987). The major modifications were that all glass parts were reduced in size (about $\frac{1}{3}$ of the original size) to allow for a smaller volume of perfusion medium and that Tygon tubing (with less adsorbance of steroids) replaced the previously used silicon rubber tubing in the parts through the pump. The medium used was M199 with Earle's salts (Gibco, Paisley) with additions of bovine serum albumin $(4 \% \mathrm{w} / \mathrm{v})$, gentamicin $\left(50 \mu \mathrm{g} \mathrm{ml}{ }^{-1}\right), \mathrm{NaHCO}_{3}$ $\left(26 \mathrm{mmol} \mathrm{l}^{-1}\right)$ and insulin $\left(0.02 \mathrm{iu} \mathrm{ml}^{-1}\right)$. The temperature of the medium was kept at $37^{\circ} \mathrm{C}$ by circulating heated water through jackets of the perfusion apparatus. The initial volume of perfusion medium was $25 \mathrm{ml}$, which was continuously oxygenated with $95 \% \mathrm{O}_{2}$ and $5 \% \mathrm{CO}_{2}$.

During perfusion, the aortic catheter was connected to the outflow part of the bubble trap and the specimen was placed in the perfusion chamber, which was covered by parafilm. The pressure was adjusted to $80 \mathrm{~mm} \mathrm{Hg}$, which gave a flow rate of $0.5-0.6 \mathrm{ml} \mathrm{min}^{-1}$. The ovaries were perfused for $1 \mathrm{~h}$ before any agents were added, to allow metabolic stabilization of the tissue. Human CG, LH and IBMX were dissolved in perfusion media and added in a volume of $0.5 \mathrm{ml}$. Samples of perfusion medium $(0.5 \mathrm{ml})$ were taken at $1,2,3,5,7$ and $20 \mathrm{~h}$, using a sampling syringe during continuous recirculating perfusion.

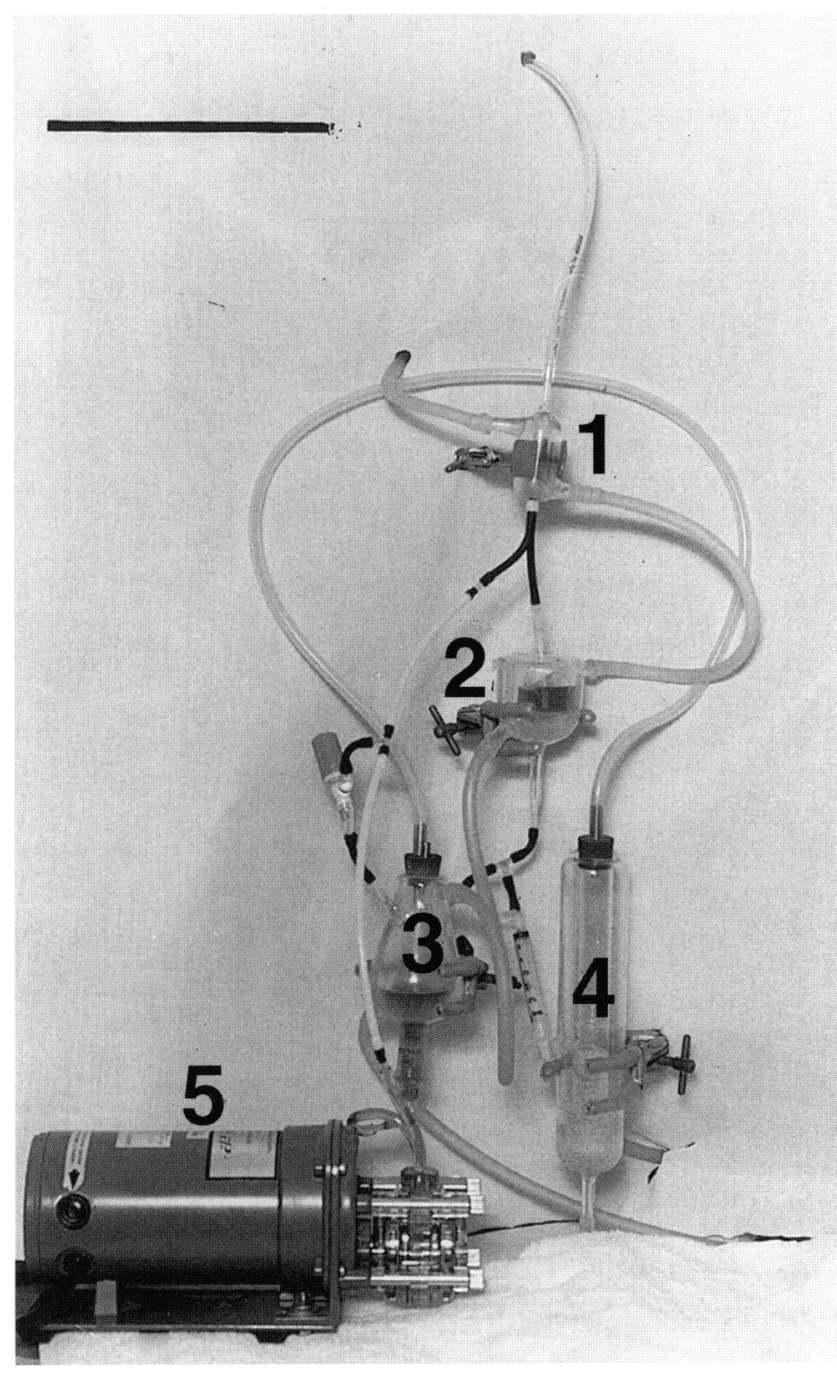

Fig. 2. Photograph of perfusion apparatus. 1, bubble trap; 2, perfusion chamber; 3 , medium reservoir/oxygenater; 4 , gas humidifier; 5 , peristaltic pump. Scale bar represents $15 \mathrm{~cm}$.

Ovulation was assessed by counting the number of oocytes in the perfusion chamber. Ovulated oocytes were examined using Nomarski differential interference contrast optics, and ova with a germinal vesicle were considered to be immature, while those with germinal vesicle breakdown were regarded as undergoing maturation (Tsafriri and Kraicer, 1972). In some experiments, an excised ovary was placed in the perfusion chamber but only superfused with medium.

\section{Assays}

Progesterone concentrations in the perfusate were analysed with a radioimmunoassay kit purchased from Bioclone, Merrickville, VIC, and oestradiol concentrations were determined using a radioimmunoassay kit purchased from Serono, Rome. Intra-assay coefficients of variation were $<7 \%$ in both assays. The lowest standards of the assays were $1.0 \mathrm{pmol}$ progesterone $\mathrm{ml}^{-1}$ and $0.05 \mathrm{pmol}$ oestradiol ml $\mathrm{ml}^{-1}$. 

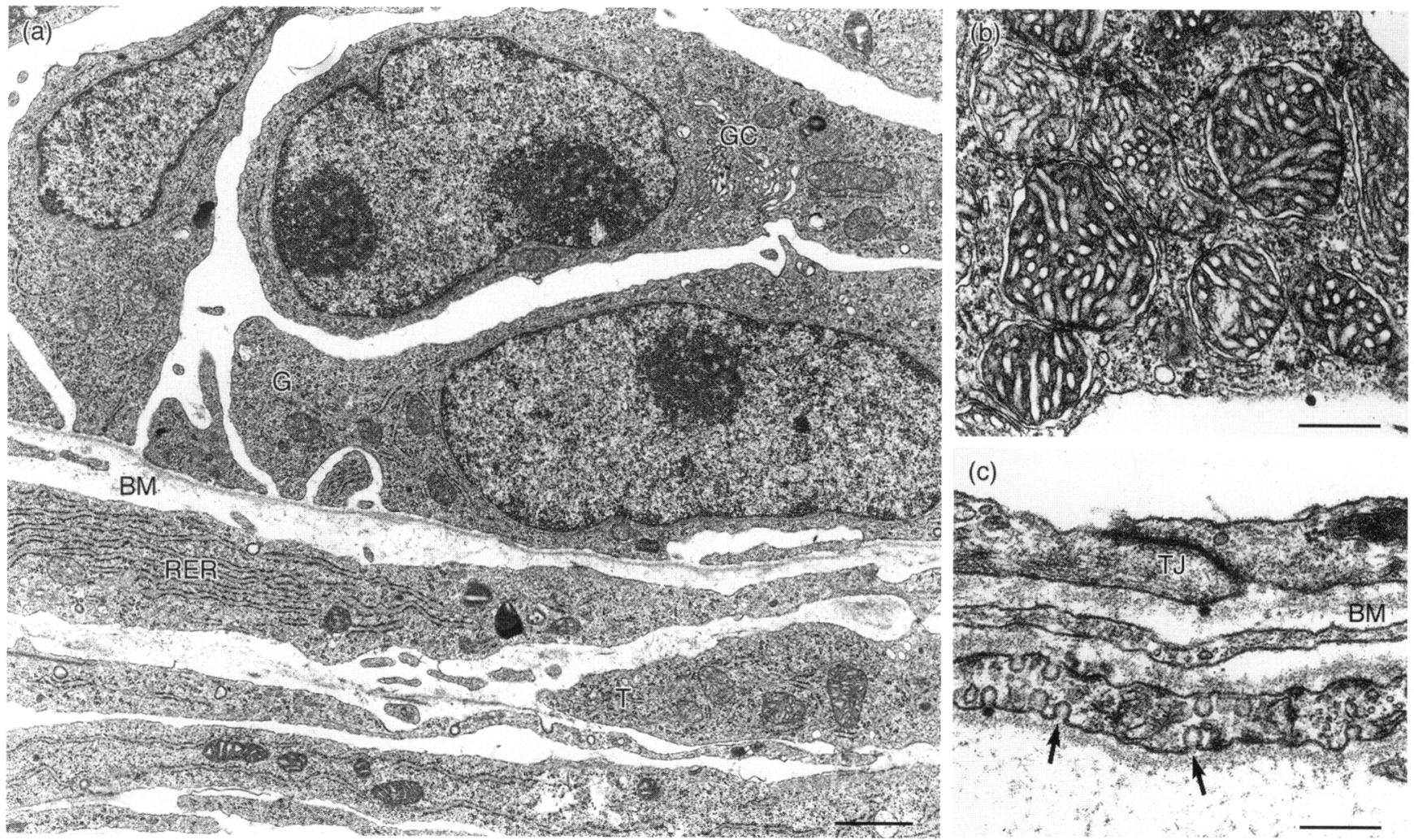

(c)

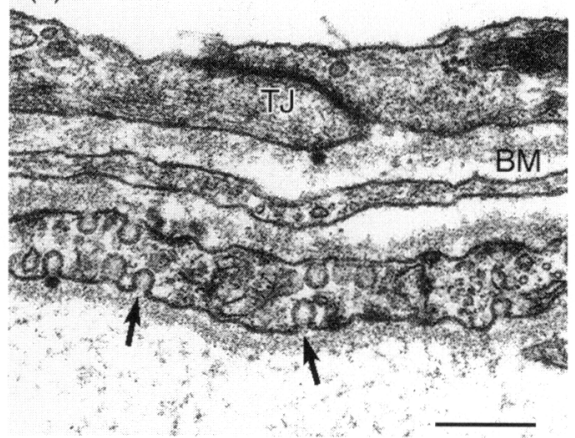

Fig. 3. Electronmicrographs of the ultrastructure of perfused mouse ovaries. (a) The granulosa $(G)$ and thecal (T) cells contain extensive arrays of rough endoplasmic reticulum (RER). A Golgi complex (GC) is evident in one cell and the basement membrane (BM) of the granulosa cell layer is intact. Scale bar represents $1 \mu \mathrm{m}$. (b) Higher magnification of mitochondria in a thecal cell. Note the tubular cristae characteristic of steroid-producing cells. Scale bar represents $0.5 \mu \mathrm{m}$. (c) A tight junction (TJ) between two endothelial cell processes. Note the pinocytotic vesicles (arrows) and basement membrane (BM). Scale bar represents $0.25 \mu \mathrm{m}$.

\section{Preparation for transmission electron microscopy}

After a $20 \mathrm{~h}$ perfusion period, unstimulated and LH-treated ovaries were perfused with $5 \%(\mathrm{w} / \mathrm{v})$ glutaraldehyde in $0.1 \mathrm{~mol}$ cacodylate buffer $\mathrm{I}^{-1}(\mathrm{pH} 7.2)$, cut into $1 \mathrm{~mm}^{3}$ pieces and then immersion-fixed at $4^{\circ} \mathrm{C}$ in the same fixative. After rinsing in cacodylate buffer, the pieces were post-fixed for $2 \mathrm{~h}$ with $1 \%(\mathrm{w} / \mathrm{v}) \mathrm{O}_{\mathrm{SO}} \mathrm{O}_{4}$ in cacodylate buffer and then stained en bloc with $1 \%(\mathrm{w} / \mathrm{v})$ uranyl acetate in $70 \%(\mathrm{v} / \mathrm{v})$ ethanol. After dehydration in a graded series of ethanol and equilibration in propylene oxide, they were embedded in Polarbed 812 resin (Fisons Scientific Equipment, Loughborough). Ultrathin sections were stained with uranyl acetate and lead citrate and examined in a Jeol 100 s electron microscope operating at $80 \mathrm{kV}$.

\section{Results}

\section{Ultrastructure of perfused ovaries}

In general, the ultrastructure of the perfused ovaries was good and there was little evidence of injury or tissue degeneration after the $20 \mathrm{~h}$ perfusion. There were no marked differences between control and LH-stimulated ovaries. The basement membranes between the granulosa and thecal layers and around the endothelial cells were intact. The nuclei of granulosa and thecal cells had smooth borders, a double nuclear envelope and nuclear pores. These cells contained active Golgi complexes, rough endoplasmic reticulum and mitochondria (Fig. 3a). Some of the mitochondria had tubular cristae, which are characteristic of steroid-producing cells (Fig. 3b), while others had transverse cristae. A few cells showed slightly swollen mitochondria, while others contained mitochondria with a very electron-dense matrix; these cells also contained large numbers of lipid droplets and were relatively devoid of rough endoplasmic reticulum (not shown). Endothelial cells around small blood vessels contained a wide array of organelles including Golgi complexes, and frequently showed pinocytotic vesicles on their adluminal and abluminal surfaces. Distinct tight junctions were present between endothelial cells (Fig. 3c).

\section{Ovulations and oocyte maturation}

Perfused unstimulated control ovaries $(n=5)$ did not ovulate. Stimulation in vitro with either hCG (50 iu), ovine LH

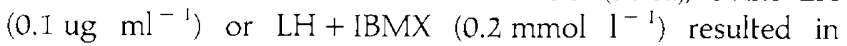
ovulations from all five ovaries in each group (Table 1). The ovulation rate was higher in the LH + IBMX group than in the other groups. All ovulated oocytes in the LH- and hCGstimulated groups exhibited germinal vesicle breakdown, while only $30 \%$ of ovulated oocytes in the LH + IBMX group were at the germinal vesicle breakdown stage. 
Table 1. Ovulations in mouse ovaries perfused in vitro

\begin{tabular}{lccc}
\hline Treatment & $\begin{array}{c}\text { Number ovulating/ } \\
\text { total number } \\
\text { in group }\end{array}$ & $\begin{array}{c}\text { Number of ovulations/ } \\
\text { treated ovary } \\
\text { (mean } \pm \text { SEM) }\end{array}$ & Range \\
\hline Control & $0 / 5$ & - & - \\
$\mathrm{hCG}^{\mathrm{a}}$ & $5 / 5$ & $2.6 \pm 0.5$ & $1-4$ \\
$\mathrm{LH}^{\mathrm{b}}$ & $5 / 5$ & $2.0 \pm 0.3$ & $1-3$ \\
$\mathrm{LH}^{+\mathrm{IBMX}}$ & $5 / 5$ & $7.4 \pm 1.2$ & $4-11$ \\
\hline
\end{tabular}

${ }^{\mathrm{a}} \mathrm{hCG}(50 \mathrm{iu})$ was added at $\mathrm{I} \mathrm{h}$.

${ }^{\mathrm{b}} \mathrm{O}$ vine $\mathrm{LH}\left(100 \mathrm{ng} \mathrm{ml}^{-1}\right)$ was added at $1 \mathrm{~h}$

'Ovine LH (100 $\left.\mathrm{ng} \mathrm{ml}^{-1}\right)$ and $3^{\prime}$-isobutyl-1-methyl xanthine (IBMX) $\left(0.2 \mathrm{mmol} \mathrm{l}^{-1}\right)$ were added at $1 \mathrm{~h}$.

Excised ovaries were superfused in an identical system to the one above to test whether perfusion of the vasculature was necessary to acquire ovulations. Four superfused hCG (50 iu)-stimulated and four unstimulated control ovaries did not ovulate.

\section{Steroid release}

The concentrations of oestradiol in the medium were below the detection limit in superfused ovaries (hCG-stimulated and control) and perfused control, LH- and hCG-stimulated ovaries at all time points. In the group of perfused LH + IBMXstimulated ovaries, there were detectable concentrations of oestradiol after $2 \mathrm{~h}$ of perfusion $\left(0.26 \pm 0.09 \mathrm{pmol} \mathrm{ml}^{-1}\right)$, which increased gradually to $0.38 \pm 0.07 \mathrm{pmol} \mathrm{ml}^{-1}$ at $20 \mathrm{~h}$. The concentration of progesterone measured in the perfusion medium represents a balance between progesterone secretion and adsorption, as progesterone in higher concentrations is rapidly adsorbed to the surfaces of the system (Bruning et al., 1981) with a $t_{1 / 2}$ of about $2.5 \mathrm{~h}$ (Brännström et al., 1987). Progesterone was released in larger quantities than oestradiol in all treatment groups. In superfused control ovaries, there were low concentrations of progesterone in the medium throughout the perfusion time $\left(3.3 \pm 1.0 \mathrm{pmol} \mathrm{ml}^{-1}\right.$ at $\left.20 \mathrm{~h}\right)$. When superfused ovaries were stimulated by hCG (50 iu), there was a slight, gradual increase in progesterone concentrations $\left(11.8 \pm 1.6 \mathrm{pmol} \mathrm{ml}^{-1}\right.$ at $\left.20 \mathrm{~h}\right)$. Perfused ovaries released markedly larger amounts of progesterone. There was a small increase in the progesterone concentration in the control group, and the addition of either LH, hCG or LH + IBMX led to a marked rapid increase in progesterone release, reaching maximal concentrations at 3-7 h (Fig. 4).

\section{Discussion}

In vitro models may contribute to the identification of locally produced paracrine factors that regulate dynamic ovarian events such as ovulation. Experiments in vivo can be difficult to perform or to interpret owing to systemic influences. By perfusion of ovaries in vitro, the organ can be kept in a functioning state over extended periods, facilitating the study of these dynamic events.

This is the first report of perfusion of mouse ovaries in vitro combined with the induction of ovulation in vitro. In earlier studies on incubated mouse Graafian follicles, a very small number of follicles with signs of ovulation was observed (Neal and Baker, 1973; Boland et al., 1995) and it is possible that some of these ruptured follicles were caused by mechanical trauma during preparation or incubation (Neal and Baker, 1973; Boland et al., 1993). In the present study, the ovarian surface was protected by the ovarian bursa during surgery, so the

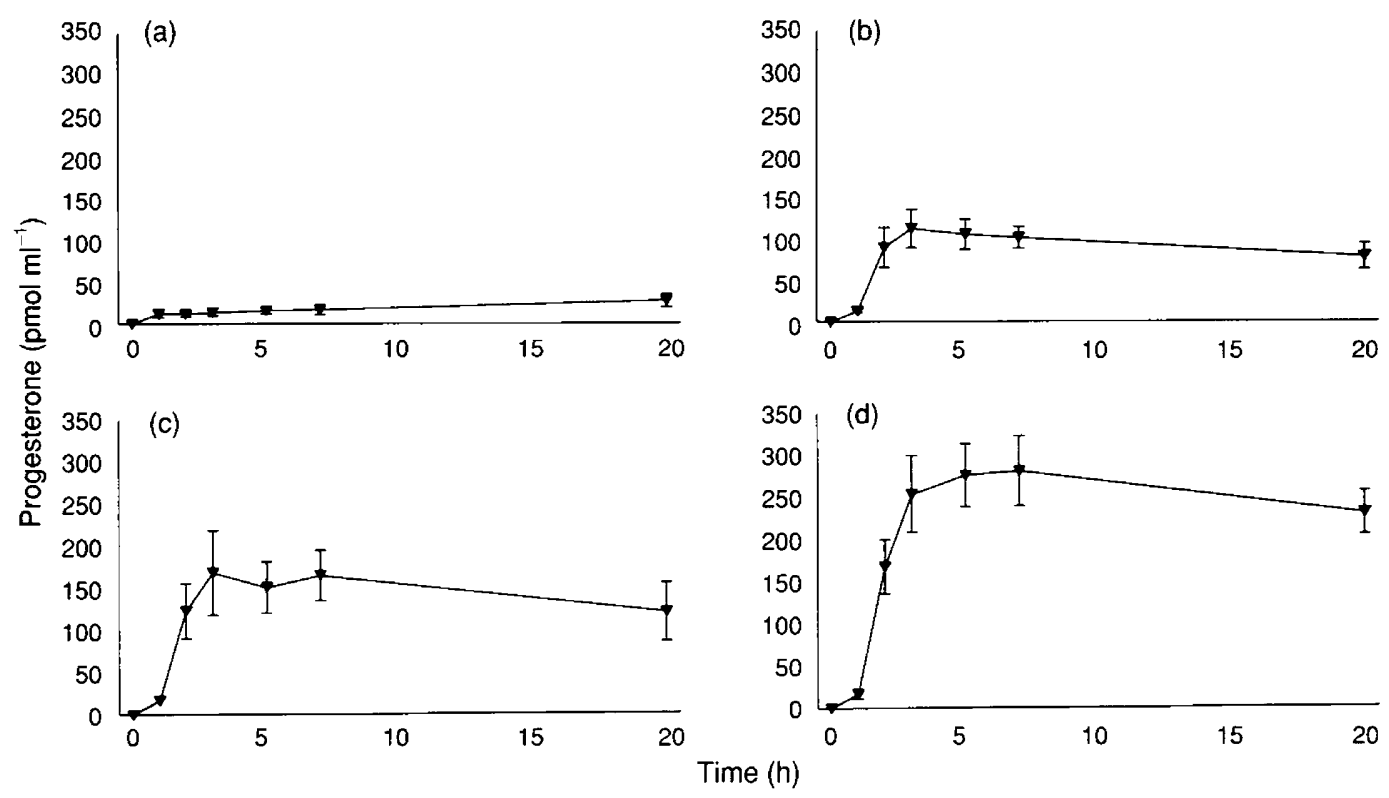

Fig. 4. Progesterone concentrations in the medium. Each symbol represents values obtained in five perfusions. Vertical bars indicate the SEM (a) control ovaries; (b) hCG-stimulated ovaries; (c) LH-stimulated ovaries; and (d) ovaries stimulated with $\mathrm{LH}$ and 3 '-isobutyl-1-methylxanthine (IBMX). 
bursa remained untouched until it was slit open before introduction of the ovary into the perfusion apparatus. Furthermore, during perfusion, the ovary was completely submerged in perfusion medium. This, in addition to the absence of ovulations from unstimulated control ovaries, rules out the possibility that ovulations from gonadotrophin-stimulated ovaries in the present study were due to mechanical injury to the follicle surface. The fact that superfused ovaries in our experimental model did not ovulate and secreted only small quantities of steroids suggests that superfusion is not a suitable method.

Perfused mouse ovaries exhibited a normal morphology after $20 \mathrm{~h}$ of perfusion. There were no signs of blood cells observed in any vessels, indicating a homogeneous perfusion. A limiting factor of perfusion in vitro is damage to endothelial cells with loss of intercellular tight junctions. In the present study, transmission electron microscopy revealed intact endothelial cells and basement membranes, indicating the absence of severe endothelial damage.

The reason for using adult cyclic mice in contrast to immature animals induced with eCG, which are commonly used in studies of reproductive functions in rats, was that at this stage the immature mice were considered too small for the extensive surgery to be carried out. However, a disadvantage of using adult cyclic animals in contrast to eCG-primed animals is that the ovary contains corpora lutea of different stages, the influence of which may complicate the interpretation of results.

The ovulation rate after treatment with only gonadotrophin was lower than that observed in vivo. However, the combined use of IBMX (to increase cAMP concentrations) and LH increased the ovulation rate to that which is normal in vivo, in accordance with observations in the rat ovary perfusion system (Brännström et al., 1989). The observation that the ovulation rate can be increased in rat ovaries perfused in vitro by addition of several blood factors such as leukocytes (Hellberg et al., 1991) and bradykinin (Brännström and Hellberg, 1989) suggests that several factors are lacking in the situation in vitro for maximal numbers of ovulations to take place. The reduction of ovulation rate in vitro can also partly be explained by a decreased flow to the ovary, owing to ligation of the ovarian branch of the uterine artery. It has been reported in rats that ligation of this artery causes a $40 \%$ reduction in ovulation rate (Peppler, 1976). In the perfusion methodology applied in the present study, the arterial side pressure is fixed and the flow will be the result of the pressure and the vascular resistance in the ovary. This technique enables the monitoring of the influence of vasoconstrictive agents on the ovarian vessels. In a slightly different perfusion system, which has been used for rabbit ovaries (Lambertson $e$ al, 1976) the arterial side pressure was not monitored and perfusion was performed with a set flow rate.

The concentrations of progesterone in the medium in the gonadotrophin-stimulated ovaries showed a marked increase in comparison to control ovaries. There was a continuous output of progesterone during the perfusion period, suggesting good viability of the ovaries. The concentration of progesterone in the medium corresponds well with concentrations in the tissue in a similar system for rat ovaries (Higuchi and Espey, 1989). The higher progesterone secretion from ovaries that had been exposed to IBMX may have been due to additional activation of preovulatory follicles or to activation of older corpora lutea.
Oestradiol concentrations were lower than progesterone concentrations and only detectable in ovaries stimulated by $\mathrm{LH}$ plus IBMX. This finding indicates that phosphodiesterase inhibition by IBMX increases the overall steroidogenic capacity of the perfused ovary. The steroid output from superfused ovaries was considerably lower than from perfused ovaries. This shows that the superfusion model is less responsive than the perfusion model in terms of steroidogenesis, and it is likely that only the surface part of the ovary is metabolically active.

In summary, we have described and characterized a model for perfusion of mouse ovaries in vitro, which enables induction of ovulation in vitro. This model could be useful in studies of ovarian function.

This work was supported by grants from the Swedish Medical Research Council (MFR 11607) and the National Health and Medical Research Council of Australia. The authors thank H. Holmes for expert secretarial assistance, N. Swann for tissue preparation and sectioning, and K. Crocker of the Centre for Electron Microscopy and Microstructure Analysis at The University of Adelaide.

\section{References}

Adashi EY, Resnick CE, D'Ercole AJ, Svoboda ME and van Wyk JJ (1985) Insulin-like growth factors as intraovarian regulators of granulosa cell growth and function Endocrine Review 6 400-420

Armstrong DT (1968) Hormonal control of uterine fluid retention in the rat American Journal of Physiology 214 764-771

Boland NI, Humpherson PG, Leese HJ and Gosden RG (1993) Pattern of lactate production and steroidogenesis during growth and maturation of mouse ovarian follicles in vitro Biology of Reproduction 48 798-806

Brännström M and Hellberg P (1989) Bradykinin potentiates LH-induced follicular rupture in the rat ovary perfused in vitro Human Reproduction 4 475-481

Brännström M and Janson PO (1991) The Biochemistry of Ovulation. In Ovarian Endocrinology pp 133-166 Ed. SG Hillier. Blackwell Scientific Publications, London

Brännström M and Norman RJ (1993) Involvement of leukocytes and immunomodulatory cytokines in the ovulatory process and corpus luteum function Human Reproduction 8 1762-1775

Brännström M, Johansson BM, Sogn J and Janson PO (1987) Characterization of an in vitro perfused rat ovary model: ovulation rate, occyte maturation, steroidogenesis and influence of PMSG priming Acta Physiologica Scandinavica 130 107-114

Brännström M, Boberg BM, Törnell J, Janson PO and Ahren K (1989) Effects of inhibitors of protein synthesis on the ovulatory process of the perfused rat ovary Journal of Reproduction and Fertility 85 451-459

Bruning PF, Jonker KM and Boereman-Baan AW (1981) Adsorption of steroid hormones by plastic tubing Joumal of Steroid Biochemistry 14 553-555

Janson PO, LeMaire WJ, Källfelt B, Holmes PV, Cajander S, Bjersing L, Wiquist N and Ahren K (1982) The study of ovulation in the isolated perfused rabbit ovary. I. Methodology and pattern of steroidogenesis Biology of Reproduction $26456-465$

Hellberg P, Thomsen P, Janson PO and Brännström M (1991) Leukocyte supplementation increases the luteinizing hormone-induced ovulation rate in the in vitro perfused rat ovary Biology of Reproduction 44 791-797

Higuchi Y and Espey LL (1989) Pattern of ovarian steroid secretion during ovulation of in vitro perfused rat ovaries with method of sampling Journal of Reproduction and Fertility $\mathbf{8 7} 821-828$

Kobayashi Y, Santulli R, Wright KH and Wallach EE (1983) In vitro fertilization of rabbit ova ovulated in vitro during ovarian perfusion Journal of Reproduction and Fertility $6841-44$

Lambertson CL, Greenbaum DF, Wright KH, and Wallach EE (1976) In vitro studies of ovulation in the perfused rabbit ovary Fertility and Sterility $\mathbf{2 7}$ 178-187

Neal P and Baker TG (1973) Response of mouse ovaries in vivo and in organ culture to pregnant mares' serum gonadotrophin and human chorionic gonadotrophin Journal of Reproduction and Fertility 33 399-410 
Paigen K (1995) A miracle enough: the power of mice Nature Medicine 1 215-220 Peppler RD (1976) Effect of uterine artery ligation on ovulation in the rat Anatomical Record 184 183-186

Romanoff EB and Pincus G (1962) Studies of the isolated perfused ovary: methods and examples of application Endocrinology 71 752-755

Sogn J. Abrahamsson G and Janson PO (1984) Release of cyclic AMP and progesterone from the isolated perfused luteal ovary of the PMSG-treated rat Acta Endocrinologica 106 265-270
Stähler E, Spätling L, Behtge HD, Daume E and Buchholz R (1974) Induction of ovulation in human ovaries perfused in vitro Archives of Gynaecology 217 $1-15$

Tsafriri A and Kraicer PF (1972) The time-sequence of ovum maturation in the rat Journal of Reproduction and Fertility $29387-393$

Vickery BH and McRae GI (1980) Synchronization of oestrus in adult female rats by utilizing the paradoxical effects of an LHRH agonist Journal of Reproduction and Fertility $60399-402$ 